REVIEW

\title{
Pathophysiology of dyslipidaemia in the metabolic syndrome
}

\author{
G D Kolovou, K K Anagnostopoulou, D V Cokkinos
}

Postgrad Med J 2005;81:358-366. doi: 10.1136/pgmj.2004.025601

The insulin resistance/metabolic syndrome is characterised by the variable coexistence of hyperinsulinaemia, obesity, dyslipidaemia, and hypertension. The pathogenesis of the syndrome has multiple origins, but obesity and sedentary lifestyle coupled with diet and still largely unknown genetic factors clearly interact to produce the syndrome. Dyslipidaemia, the hallmark of the metabolic syndrome, includes increased flux of free fatty acids, raised triglycerides, apolipoprotein $B$, and small dense low density lipoprotein, and decreased high density lipoprotein cholesterol. The widely prevalent nature of the metabolic syndrome emphasises the importance of its diagnosis and treatment. This review analyses the clinical and dynamic features of this syndrome in the aspect of dyslipidaemia and its management.

See end of article for authors' affiliations

Correspondence to: Dr G D Kolovou, Onassis Cardiac Surgery Centre, 356 Sygrou Avenue 176 74 Athens, Greece; genkolovou@mail.gr

Submitted 15 June 2004 Accepted

1 November 2004
$\mathrm{T}$ he insulin resistance/metabolic syndrome (MetS) is characterised by the variable coexistence of hyperinsulinaemia, obesity, dyslipidaemia, and hypertension. ${ }^{12}$ Other features of the syndrome include the proinflammatory states, microalbuminuria, and hypercoagulability. ${ }^{3-5}$ Despite abundant research and clinical application of the MetS, the various cut offs for its components have varied widely. The pathogenesis of the syndrome has multiple origins. Obesity and sedentary lifestyle coupled with diet as well as still largely unknown genetic factors clearly interact to produce the syndrome. ${ }^{6}$ In 1988, Reaven introduced the term syndrome $X$, with insulin resistance as a common denominator for the syndrome. ${ }^{7}$ In addition to syndrome $X$, several other synonyms have been proposed such as deadly quartet, DROP syndrome (dyslipidaemia, insulin resistance, obesity, and high blood pressure), multiple metabolic syndrome, and insulin resistance syndrome. ${ }^{128}$ To aid in the research and clinical application of the MetS, the World Health Organisation consultations for the classification of diabetes and its complications and the National Cholesterol Education Program (NCEP) Adult Treatment Panel (ATP) III expert panel have published definitions. ${ }^{9}{ }^{10}$ The latter is the most widely used. Table 1 summarises the MetS definitions of both the WHO and NCEP ATP III. Additionally, the NCEP ATP III guidelines define the MetS as a new secondary target for cardiovascular risk reduction therapy, recommending both lifestyle modification and treatment of individual risk factors.

\section{PREVALENCE}

Using the WHO definition and data from the national health and nutrition examination survey III (NHANES III) and the NCEP ATP III criteria, the age adjusted prevalence of the MetS in the USA is currently estimated at $24 \%$ and increases to $44 \%$ in adults who are over 60 years. $^{9-11}$ The prevalence of two or more Mets components is $43.9 \%$, showing that a large group is at risk for its development. Based on the data from the 2000 US census, an estimated 47 million US residents have the MetS. ${ }^{11}$ There is a 3.2 relative risk of acute coronary events in subjects with characteristics of the MetS (body mass index $\geqslant 25.0 \mathrm{~kg} / \mathrm{m}^{2}$ and waist to hip ratio $\geqslant 0.91) .{ }^{12}$ In the women's angiographic vitamin and oestrogen trial the prevalence of the MetS was $60 \%$ and clinical cardiovascular events were significantly more frequent compared with those without MetS. ${ }^{13}$ However, going throughout the studies recently published the prevalence of the MetS varies from $7 \%$ to $84 \% .^{14}{ }^{15}$ The criteria involved in the MetS, especially type 2 diabetes mellitus, as well as other parameters such as age, sex, study's populations, and ethnic differences may explain these differences. For example, the prevalence of the MetS among American adults seems to be the highest in Mexican American women $(33 \%)$ and the lowest in white American women $(21 \%) .{ }^{16}$ The prevalence of coronary heart disease or cardiovascular disease also varies. These variations suggest that some people have a genetic predisposition that leaves them more susceptible to the development of the metabolic disturbances produced by the Western lifestyle. An example of this can be found in the Pima Indians. The group that moved to Arizona 7001000 years ago and progressively adopted a Western diet, by the age of 35 developed obesity in $>85 \%$ and diabetes in $>50 \%$ in contrast with the group who still lives in Mexico and is characterised by a traditional lifestyle, where obesity and diabetes do not seem to be an important health problem. ${ }^{17}$

The MetS is a multifactorial complex trait that is influenced by both environmental and genetic factors. Mutations and polymorphisms in the genes associated with insulin resistance, adipocyte abnormality, hypertension, lipid abnormalities may underlie the aetiological basis of the MetS. Table 2 lists some of the genes associated with the MetS. The diagnosis of the MetS seems

Abbreviations: MetS, metabolic syndrome; LDL, low density lipoprotein; HDL, high density lipoprotein; VLDL, very low density lipoprotein; apo, apoliprotein; TG, triglyceride 


\begin{tabular}{|c|c|}
\hline WHO ${ }^{\circ}$ & ATP $I I^{10}$ \\
\hline $\begin{array}{l}\text { One of the following } \\
\text { Insulin resistance } \\
\text { HOMA-IR } \geqslant 2.5 \\
\text { Impaired glucose tolerance } \\
2 \text { hour OGT } 8-11 \mathrm{mmol} / \mathrm{I} \\
\text { Type } 2 \text { diabetes mellitus } \\
\text { Fasting glucose } \geqslant 7 \mathrm{mmol} / / \text { or } \\
2 \text { hour OGTT } \geqslant 11 \mathrm{mmol} / \mathrm{I} \\
\text { Plus at least two of the following } \\
\text { Blood pressure } \\
\geqslant 140 / 9 \mathrm{~mm} \mathrm{Hg} \\
\text { BMI } \\
\geqslant 30 \mathrm{~kg} / \mathrm{m}^{2} \text { or } \\
\text { Waist to hip ratio } \\
\text { Men }>0.90 \\
\text { Women }>0.85 \\
\text { Fasting triglycerides } \\
\geqslant 1.7 \mathrm{mmol} / / \text { and } / \text { or } \\
\text { Low serum } \mathrm{HDL} \text { concentration } \\
\text { Men }<0.9 \mathrm{mmol} / \mathrm{I} \\
\text { Women }<1 \mathrm{mmol} / \mathrm{I} \\
\text { Albumin creatinine ratio } \\
\text { Men }>2.5 \mathrm{mg} / \mathrm{mmol} \\
\text { Women }>3.5 \mathrm{mg} / \mathrm{mmol}\end{array}$ & $\begin{array}{l}\text { At least three of the following } \\
\text { Waist circumference } \\
\text { Men }>102 \mathrm{~cm} \\
\text { Women }>88 \mathrm{~cm} \\
\text { Fasting triglycerides } \\
\geqslant 1.7 \mathrm{mmol} / / \\
\mathrm{HDL} \text { cholesterol } \\
\text { Men }<1 \mathrm{mmol} / \mathrm{I} \\
\text { Women }<1.3 \mathrm{mmol} / \mathrm{I} \\
\text { Blood pressure } \\
\geqslant 130 / 85 \mathrm{~mm} \mathrm{Hg}\end{array}$ \\
\hline
\end{tabular}

HOMA, homoeostasis model assessment; OGGT, oral glucose tolerance test; BMl, body mass index. HOMA-IR, fasting serum insulin $(\mu \mathrm{U} / \mathrm{ml}) \times$ fasting plasma glucose $(\mathrm{mmol} / \mathrm{l}) / 22.5$.

to identify substantial additional cardiovascular risk above and beyond the individual risk factors. Therefore, the clinical diagnosis of the MetS may be a valuable tool for identification of the elusive high risk patients.

\section{DYSLIPIDAEMIA IN THE MetS}

Dyslipidaemia, the hallmark of the MetS, is summarised as (a) increased flux of free fatty acids, (b) raised TG values, (c) low high density lipoprotein (HDL) cholesterol values, (d) increased small, dense low density lipoprotein (LDL) values, and (e) raised apolipoprotein (apo) B values (table 3). ${ }^{31}$ Dyslipidaemia is widely established as an independent risk factor for cardiovascular disease. ${ }^{32}$ Low HDL cholesterol and hypertriglyceridaemia have been found to be independently and significantly related to myocardial infarction/stroke in patients with MetS. ${ }^{33}$ Additionally, a combination of high fasting glucose and low HDL cholesterol were shown to have primary predictive ability for coronary heart disease. ${ }^{34}$ Moreover, in the study of Sacco and colleagues, the role of HDL cholesterol values, as an important modifiable stroke risk factor, was further supported. ${ }^{35}$ The dyslipidaemia in MetS patients may be caused by a combination of overproduction of very low density lipoprotein (VLDL) apo B-100, decreased catabolism of apo B containing particles, and increased catabolism of HDL-apo A-I particles. These abnormalities may be the consequence of a global metabolic
Table 2 Genes associated with the metabolic syndrome

\begin{tabular}{|c|c|}
\hline MetS characteristics & Genes \\
\hline Abdominal obesity & $\begin{array}{l}\text { Leptin, }^{18} \mathrm{POMC},{ }^{18} \mathrm{PCl},,^{18} \text { melanocortin } \\
\text { receptor } 4{ }^{18} \text { leptin receptor, }{ }^{18} \text { adiponectin, } \\
\text { PPAR } 22^{20}{ }^{20} \mathrm{TNF} \alpha^{20}\end{array}$ \\
\hline Hypertriglyceridaemia & $\begin{array}{l}\text { UCP1 }{ }^{20}{ }^{20} \mathrm{LLL}^{20}{ }^{21} \beta_{2} \text { and } \beta_{3} \text { adrenergic } \\
\text { receptor. } \\
\text { CETP }{ }^{20}{ }^{23} \text { FATPI, }{ }^{20} \text { apo CIII, }{ }^{22} \text { apo AV, }\end{array}$ \\
\hline $\begin{array}{l}\text { Low HDL cholesterol } \\
\text { Hypertension }\end{array}$ & 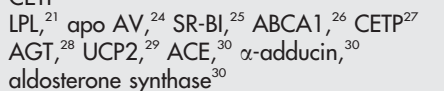 \\
\hline $\begin{array}{l}\text { Impaired fasting } \\
\text { glucose }\end{array}$ & Adiponectin, ${ }^{19} 20 \mathrm{TNF} \alpha^{20}$ \\
\hline
\end{tabular}

POMC, pro-opiomelanocortine; $\mathrm{PCl}$, prohormone convertase 1; $\operatorname{PPAR} \gamma_{2}$, peroxisome proliferators activated receptor $\gamma_{2} ; \operatorname{TNF} \alpha$, tumour necrosis factor $\alpha_{;} \mathrm{UCPI}$, uncoupling protein 1; LPL, lipoprotein lipase; FATP1, fatty acid transport protein 1; apo, apolipoprotein; CETP, cholesteryl ester transfer protein; SR-BI, scavenger receptor class B type I; $A B C A 1$, ATP binding cassette $A 1$ transporter; $A G T$, angiotensinogen; UCP2, uncoupling protein 2; $A C E$, angiotensin converting enzyme.

effect of insulin resistance. Although the underlying mechanisms for this pattern are not fully understood, a cascade of events has been proposed for the observed phenotype, which ties in with all of the abnormalities present in these disorders.

\section{Increased free fatty acids}

The primary defect is probably focused in the inability to incorporate the free fatty acids to TGs by the adipose tissue (inadequate esterification). ${ }^{31}$ This results in reduced fatty acid trapping and consequent retention by the adipose tissue. The insulin resistance also causes reduced retention of free fatty acids by the adipocytes. Both these abnormalities lead to increased flux of free fatty acids back to the liver (fig 1). However, some studies have shown that hepatic fatty acid metabolism is required for the development of insulin resistance. $^{8}$

Adipose tissue, for a long time, was regarded as a comparatively passive side of energy storage (accumulated in the form of TGs). However, recent studies show that adipose tissue is an endocrine organ producing various proteins (adipocytokines). ${ }^{36}$ Adipocytokines include leptin, angiotensinogen, tumour necrosis factor $\alpha$, interleukin 6, plasminogen activator-inhibitor 1 , transforming growth factor $\beta$, adipsin, adiponectin, resistin. These proteins are increased (with the exception of adiponectin, which decreases) in obesity and, at least under experimental settings, possibly can induce obesity related insulin resistance or diabetes..$^{37}{ }^{38}$ Additionally, adipose tissue is a prominent source of cholesteryl ester transfer protein. ${ }^{39}$ Cholesteryl ester transfer protein is an important determinant of lipoprotein composition because of its capacity to mediate the transfer of cholesteryl esters from cholesteryl ester rich lipoproteins to TG rich lipoproteins in exchange for TGs. ${ }^{40}$ In obese subjects, cholesteryl ester transfer protein activity and mass are increased. $^{41}$

Table 3 Fasting abnormalities in lipid, lipoprotein, apolipoprotein values, and in enzymes or proteins involved in the metabolic syndrome

\begin{tabular}{llll}
\hline Lipids & Lipoproteins & Apolipoprotein & Enzymes, proteins \\
\hline Increased FFA & Increased VLDL & $\begin{array}{l}\text { Increased apo B-100 } \\
\text { and apo B-48 } \\
\text { Decreased apo A }\end{array}$ & Decreased L \\
Increased TGs & $\begin{array}{l}\text { Increased small dense LDL } \\
\text { Decreased HDL }\end{array}$ & $\begin{array}{l}\text { Increased HL } \\
\text { Increased CETP }\end{array}$ \\
\hline
\end{tabular}

FFA, free fatty acid; TG, triglyceride; VLDL, very low density lipoprotein; LDL, low density lipoprotein; HDL, high density lipoprotein; apo, apolipoprotein; LPL, lipoprotein lipase; HL, hepatic lipase; CETP, cholesteryl ester transfer protein. 


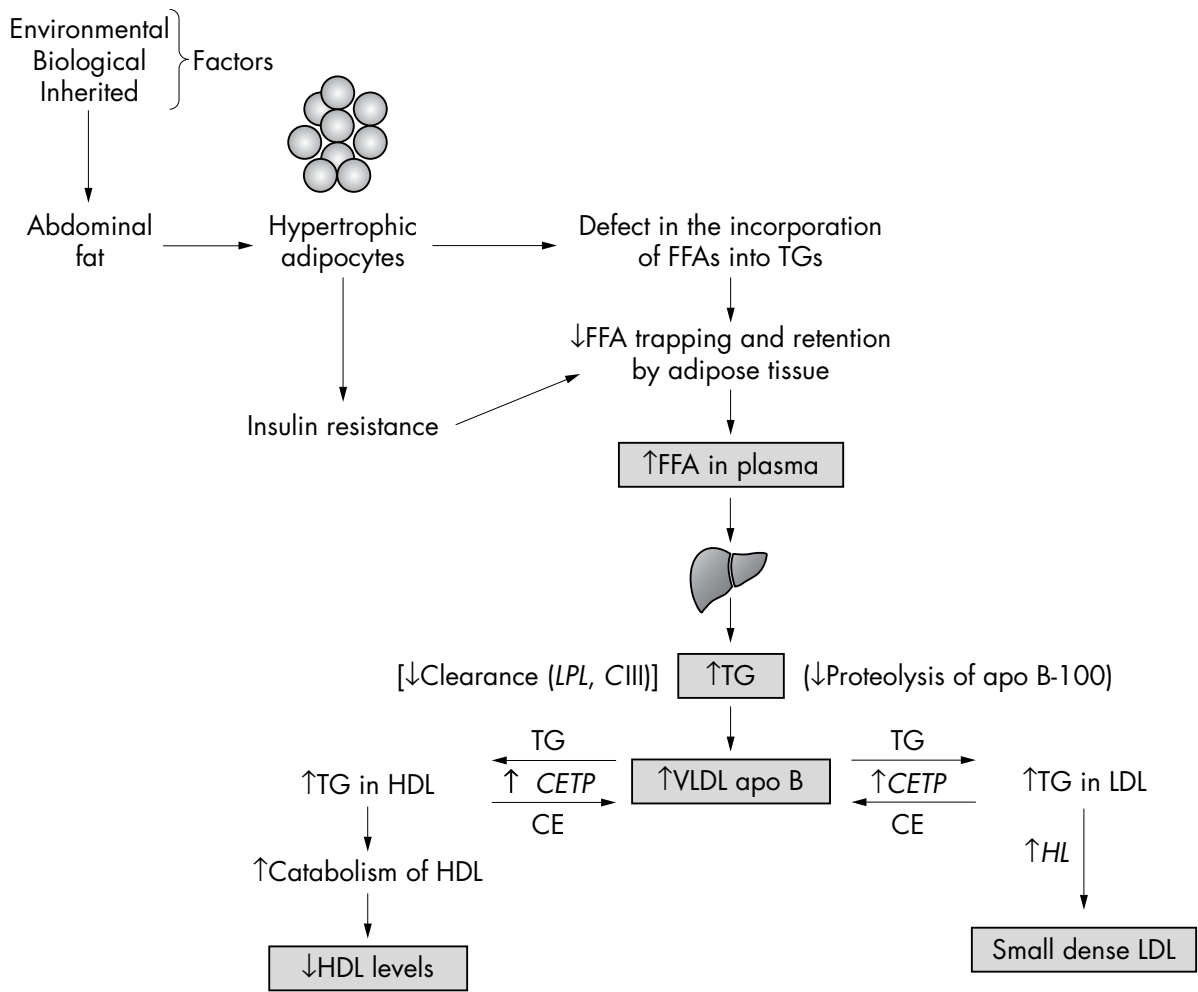

Figure 1 Schematic representation of dyslipidaemia of metabolic syndrome. FFA, free fatty acid; TG, triglyceride; LPL, lipoprotein lipase; CIII, apolipoprotein CIII; apo, apolipoprotein; HDL, high density lipoprotein; CETP, cholesteryl ester transfer protein; CE, cholesteryl ester; VLDL, very low density lipoprotein; LDL, low density lipoprotein; HL, hepatic lipase.

\section{Increased TGs}

Increased flux of free fatty acids from the periphery to the liver in the insulin resistant state stimulates hepatic TG synthesis, which in turn promotes the assembly and secretion of TG containing VLDL, ${ }^{42}$ as well as the apo B production in the liver. ${ }^{31}{ }^{43}$ Under normolipidaemic conditions in humans, VLDL secretion is affected by TG and cholesterol availability and recent studies suggest an association between cholesterol synthesis and production of smaller VLDL particles $\left(\mathrm{VLDL}_{2}\right){ }^{44}$ While insulin suppresses the formation of large VLDL particles, VLDL 1 does not have any impact on the production of the smaller $\mathrm{VLDL}_{2}$ fraction. ${ }^{45}$ When insulin resistance occurs, the high insulin values make the liver resistant to the inhibitory effects of insulin on VLDL secretion. ${ }^{46}$

Visceral obesity and increased intra-abdominal fat have been shown to precede development of insulin resistance. ${ }^{47}$ Increasing insulin resistance is proposed to be the precursor for two events. Firstly, in the presence of insulin resistance, the visceral adipocyte is more sensitive to the metabolic effects of the lipolytic hormones glucocorticoids and catecholamines ${ }^{48}$ This hormonal lipolytic activity produces an increased release of free fatty acids into the portal system, which serves as hepatic substrate to assemble TGs and TG rich VLDLs. Secondly, increasing insulin resistance leads to increased production of apo B, the major protein of LDL, and as a consequence to the increased synthesis and secretion of TG containing VLDL cholesterol particles. ${ }^{49}$ Experiments in cell cultures suggest that VLDL assembly is complex and entails a two step process. ${ }^{45}$ Firstly, a small lipoprotein particle containing little TG is formed in the rough endoplasmic reticulum, and secondly, the bulk of the TG core is added to this at the junction of the rough and smooth endoplasmic reticulum. It is possible that the release of small VLDL follows the addition of a comparatively small quantity of TG (or of cholesteryl ester) to the nascent particle while large VLDL is formed by the addition of a substantial TG core in a second quantum step. In subjects with a low circulating concentration of TG, the liver has insufficient TG to assemble a $\mathrm{VLDL}_{2}$ sized particle and intermediate density lipoprotein/ LDL are secreted. The substantial decrease in clearance rates of both VLDL $\mathrm{VL}_{1}$ and VLDL 2 appears as plasma TG rises leading to accumulation of large VLDL particles. ${ }^{50}$ This fall off of clearance rates is likely to reflect the rates of lipolysis and could be attributable to a change in lipoprotein lipase activity (decreased in insulin resistance state) and other factors such as the apoC-II content or the apoCII/CIII ratio (modulators of lipoprotein lipase activity) in VLDL. ${ }^{51}$

However, studies in animals and humans are needed in which the impact of hepatic TG synthesis on VLDL TG production is carefully assessed. It is probable that the causes of raised TG values in the MetS are multifactorial and not simply a function of increased free fatty acid flux to the liver.

\section{Small dense LDL}

In the insulin resistant state, the LDL levels are usually within normal limits or only mildly raised; however the LDL particle is often of abnormal composition (small, dense LDL). The underlying abnormality causing small dense LDL is hypertriglyceridaemia. It has been found that small dense LDL is not seen until plasma TG levels exceed $1.5 \mathrm{mmol} / \mathrm{l}^{52}$ Under these conditions, large TG rich VLDL $\left(\mathrm{VLDL}_{1}\right)$ molecules accumulate. When $\mathrm{VLDL}_{1}$ is lipolysed by lipoprotein lipase, a population of LDL particles with changed apo B conformation is produced. These particles fail to bind efficiently to LDL receptors and so have a prolonged residence time in the circulation. By the action of cholesteryl ester transfer protein, cholesteryl esters are replaced by TG in LDL and HDL particles (fig 1). TG rich LDL is a good substrate for hepatic lipase that finally generates small dense LDL, which is associated with increased cardiovascular risk..$^{52}$ Many studies have shown that small, dense LDL particles have 
proatherogenic properties such as: (a) reduced LDL receptor mediated clearance, (b) increased arterial wall retention, (c) increased susceptibility to oxidation. ${ }^{54}$ The heterogeneity of LDL is based on the variable content of the cholesteryl ester molecules in the core of LDL, while the absolute amount of apo B on the surface of LDL may remain unchanged. ${ }^{49}$ As a result, the LDL particles are not only small and dense but also comparatively enriched in apo B molecule compared with normal LDL. In the increased TG state, small dense LDL with hyperapolipoprotein B is more likely to be formed. ${ }^{49}$ In the Johns Hopkins coronary artery disease study, higher apo B levels predicted coronary heart disease better than did LDL cholesterol. ${ }^{55}$ Hyperapobetalipoproteinaemia was the most prevalent lipoprotein phenotype in the Johns Hopkins coronary artery disease study population and was found in about $33 \%$ of patients with premature coronary heart disease..$^{56}$

\section{Low HDL cholesterol}

Low HDL cholesterol in patients with the MetS is often considered as secondary to raised $\mathrm{TG}^{1}{ }^{1}$ In the presence of increased plasma TG levels, the cholesteryl ester transfer protein mediates TG-cholesteryl ester exchange between LDL and VLDL, as already mentioned above. Similar lipid exchange is taking place between VLDL and HDL particles, forming TG rich HDL (fig 1). These TG rich but cholesterol depleted HDLs are more prone to be catabolised. They undergo hydrolysis of their TG component and dissociation of their protein component, apo A (the main protein of HDL). ${ }^{57}$ There are additional mechanisms that contribute to the low HDL cholesterol levels. One possibility is that changed lipid flux in the liver attributable to insulin resistance may reduce the hepatic production of apo A. ${ }^{1}$ However, there are studies showing that the diameter of HDL is affected by insulin resistance (see section of familial combined hypercholesterolaemia). Alternatively, the insulin resistance may cause the destabilisation of ATP binding cassette Al transporter protein, a key molecule that mediates the transfer of cellular phospholipids and cholesterol to apo A for the formation of mature and functional HDL particles. ${ }^{26}$ Mutations in the ATP binding cassette Al transporter are associated with Tangier disease, which is characterised by extremely low HDL cholesterol levels. ${ }^{58}$ In the absence of sufficient cholesterol efflux, apo A is rapidly cleared from the circulation by the kidneys. The consequence of that is low HDL cholesterol in plasma, whose pleiotropic (antioxidant, anti-inflammatory, and other) effects besides the reverse cholesterol transport, have been recently established. ${ }^{31} 59$ Furthermore, the increase of HDL cholesterol levels with lipid lowering drugs has been shown to be beneficial. ${ }^{606}$ Another possibility is that people with the MetS, even with normal fasting TG levels, have frequently abnormal postprandial responses to dietary fat. ${ }^{62}$ This transient increase of TGs increases cholesteryl ester transfer protein mediated lipid exchange and formation of HDL particles, as described above.

\section{Postprandial lipaemia}

Under conditions of insulin resistance, the antilipolytic effect of insulin on adipose tissue is weak. ${ }^{63}$ This can explain the raised free fatty acid levels seen postprandially. There is a progressive increase in plasma free fatty acid levels, which results in an eight hour plasma free fatty acid concentration that remains above fasting levels. ${ }^{64}$ Additionally, insulin resistance has two potential effects on chylomicron remnant metabolism, the main lipoprotein formed postprandially. Firstly, it downregulates LDL receptor expression, and secondly, it increases hepatic cholesterol synthesis and VLDL secretion. ${ }^{656}$ These effects increase competition between chylomicron and VLDL remnants for hepatic receptors, thereby impairing the uptake of chylomicron remnants by this pathway.$^{67}$ Another possible explanation is that the disturbances in TG postprandially may be related to the cholesterol homoeostasis. The hepatic cholesterol synthesis and intestinal cholesterol absorption are responsible for the cholesterol content in the liver. The increased intestinal cholesterol absorption reduces hepatic cholesterol synthesis and as a consequence the secretion of VLDL decreases and the LDL receptors are upregulated ${ }^{68}$ The upregulation of LDL receptors may increase the removal of both chylomicron and VLDL remnants. In the postprandial state of subjects with the MetS, the increased hepatic cholesterol synthesis and the decreased intestinal cholesterol absorption result in a nondecrease of the catabolism of TG remnants. ${ }^{69}$ Studies have shown that abnormal postprandial lipaemia is found in patients with coronary heart disease, and other conditions related to an increased risk of cardiovascular disease. ${ }^{69-71}$

\section{TYPE 2 DIABETES, FAMILIAL COMBINED HYPERLIPIDAEMIA, AND THE METS \\ Type 2 diabetes}

The pathophysiology of the development of type 2 diabetes mellitus is complex, multifactorial, and develops over a protracted period of time. Resistance to the action of insulin arises first. It is believed that obesity leads to insulin resistance and increased circulating insulin concentrations over time. ${ }^{47}$ Hyperglycaemia occurs later, as pancreatic insulin secretion eventually fails to provide sufficient insulin for the metabolic needs of the body. It seems that at some point a loss of control of blood glucose begins to emerge, resulting in dietary glucose intolerance. This ultimately results in type 2 diabetes. ${ }^{72}$ It is known that obese people may develop different degrees of insulin resistance, and not all people develop glucose intolerance. The factors that make some people more likely to develop type 2 diabetes mellitus are not well understood at the present time. A strong family predisposition is known to exist. Type 2 diabetes mellitus has long been considered a disease of adults. ${ }^{73}$ During the past 10 years, however, an increasing frequency in the occurrence of type 2 diabetes mellitus has been reported in adolescents. ${ }^{74}$ The lipid and lipoprotein abnormalities seen in type 2 diabetes are similar to those found in the MetS, but more severe. The raised TG rich lipoproteins are attributable to increased availability of free fatty acids in the liver. Raised levels of free fatty acids produce lipotoxicity, which hampers the glucose induced insulin secretion and worsens the insulin resistance. $^{75}$ Furthermore, the increased TG causes the formation of small dense LDL particles and reduction of HDL cholesterol. Patients with diabetes mellitus have higher risk for cardiovascular events compared with those without diabetes mellitus. About $80 \%$ of deaths of patients with diabetes mellitus are caused by cardiovascular disease. ${ }^{76}$ These data support the ATP III guidelines for treating patients with diabetes mellitus as aggressively as patients without diabetes mellitus but with myocardial infarction. ${ }^{10}$

\section{Familial combined hyperlipidaemia}

The metabolic abnormalities associated with the MetS are also present in patients with familial combined hyperlipidaemia. Familial combined hyperlipidaemia is characterised by a varied expression of hypertriglyceridaemia and hypercholesterolaemia. ${ }^{77}$ It is a highly atherosgenic disorder affecting $1 \%-$ $2 \%$ of the Western world and is found in up to $10 \%$ of patients with premature myocardial infarction. Familial combined hyperlipidaemia was originally described in families of myocardial infarction survivors by the presence of hypertriglyceridaemia, hypercholesterolaemia, or both in the affected family members as a monogenic disorder. ${ }^{78}$ However, the inheritance of the familial combined hyperlipidaemia associated phenotype has been shown to be 
complex. The three major lipoprotein abnormalities observed in the MetS (increased fasting and postprandial TG rich lipoproteins, decreased HDL, and a shift to small, dense LDL particles, proved to contribute to the pathogenesis of atherosclerosis) are probably the same in familial combined hyperlipidaemia. Insulin resistance is often seen in patients with familial combined hyperlipidaemia and is associated with impaired suppression of lipolysis by hormone sensitive lipase in adipocytes, producing an increased flux of free fatty acids to the hepatocyte, culminating in increased synthesis of VLDL. Insulin resistance, which also diminishes lipoprotein lipase activity, as mentioned before, would amplify the extent of hypertriglyceridaemia. Obesity is seen in patients with familial combined hyperlipidaemia, independently of insulin resistance, which would further contribute to hyperlipidaemia. Increased insulin concentrations are associated with the phenotype of smaller diameter HDL particles, but not with concentrations of apo A-I or apo A-II (main proteins of HDL particle). This suggests the existence of genes, which pleiotropically influence variation in both HDL and insulin levels, contributing to the clustering of proatherogenic traits in insulin resistance states. ${ }^{79}$ In 2001 , the third workshop on familial combined hyperlipidaemia redefined this syndrome. ${ }^{80}$ Hypertriglyceridaemia and small dense LDL were characterised as the underlying metabolic defects. The hypertriglyceridaemia in familial combined hyperlipidaemia can be attributed to multiple factors. Many patients present a significant reduction of lipoprotein lipase, responsible for hydrolysis of TG in chylomicrons and VLDL and others an overproduction of apo B. This overproduction of apo B cannot be explained only by the MetS phenotype but probably specific genes are involved..$^{81}$ Additionally, patients with familial combined hyperlipidaemia also manifest increased plasma free fatty acids that accompany the delayed removal of postprandial lipoproteins.

\section{MANAGEMENT OF DYSLIPIDAEMIA OF THE METS}

There are several non-pharmacological as well as pharmacological interventions that may increase sensitivity of insulin and therefore improve lipoprotein abnormalities.

\section{Lifestyle changes}

Weight reduction, increased physical activity, and moderate alcohol intake are first line treatments to improve lipid abnormalities (effectively reduce plasma TG and LDL cholesterol, and raise HDL cholesterol) in the MetS. In visceral obesity, weight loss reduces VLDL-apoB secretion and reciprocally upregulates LDL-apoB catabolism, probably because of reduced visceral fat mass, increased insulin sensitivity, and decreased hepatic lipogenesis. ${ }^{82}$ Although, even a $10 \%$ reduction of body weight can improve insulin sensitivity, it is generally desirable to reduce weight to the ideal level, achieving body mass index $<25 \mathrm{~kg} / \mathrm{m}^{2}$. According to the amount of exercise, even the low levels of exercise (walking for 30-45 minutes three or more times a week) are useful in improving insulin sensitivity. The foundation for treatment of dyslipidaemia is dietary modification such as reduction of saturated fat, cholesterol, and overall caloric intake. Despite the general interest in the MetS, comparatively few studies have focused on the influence of insulin resistance on lipid and lipoprotein response to dietary intervention. Knopp et al found a decreased LDL cholesterol response to a low fat diet in subjects with markers of insulin resistance. ${ }^{83}$ However, underlying mechanisms are still not very clear. The cholesterol absorption and synthesis represents two important, interrelated regulatory mechanisms in cholesterol homoeostasis, and both are affected by overall diet. Changes in one of the pathways may result in compensatory changes in the other, such as an increase in hepatic cholesterol synthesis seen during selective inhibition of cholesterol absorption. ${ }^{84}$ Furthermore, inhibition of both these pathways by combination of cholesterol synthesis inhibitors (3-hydroxy-3 methyl glutaryl coenzyme A reductase inhibitors (statins), and the recently available cholesterol absorption blocker (ezetimibe), has proved synergistic in reducing LDL cholesterol levels. ${ }^{84}$ Only a limited number of studies have evaluated a possible link between cholesterol absorption and insulin resistance in human..$^{85}$ During weight reduction, cholesterol absorption increased in parallel with improvements in glucose metabolism parameters, suggesting that low cholesterol absorption could be an additional feature of the MetS. ${ }^{85}$ Recently, a relation between cholesterol absorption and body weight in patients with type 2 diabetes was reported but also in non-diabetic subjects, obesity was associated with reduced dietary cholesterol absorption, possibly because of an increased biliary cholesterol secretion. Furthermore, patients with the MetS had a low campesterol/ cholesterol ratio, indicative of reduced cholesterol absorption.$^{86}$ This ratio was inversely correlated with plasma levels of TG, remnant cholesterol, and apo B48.

Another useful tool in reduction of serum TG levels is $\omega-3$ fatty acids. High dose $\omega-3$ fatty acids ( 6 to 12 g/day) provide $40 \%$ to $80 \%$ reductions in serum TG levels. The mechanism is unknown. Although dietary intake of 9 to $12 \mathrm{oz}$ salmon per day can provide this benefit, it is more easily achieved by concentrated fish oil supplements.

\section{Lipid changing drugs}

Therapeutic improvements in lipid and lipoprotein profiles in MetS can be achieved by several mechanisms of action, including decreased secretion and increased catabolism of apo B, as well as increased secretion and decreased catabolism of apo A-I.

There is evidence supporting the use of three major groups of lipid changing drugs, namely nicotinic acid (niacin), fibric acid derivatives (fibrates), and statins for the treatment of MetS (table 4).

Niacin effectively treats each of the common lipid abnormalities found in the MetS, and much progress has recently been made in understanding its mechanisms of action. It is known to lower plasma cholesterol and TG levels, reducing VLDL and LDL cholesterol levels. Niacin is also effective in raising HDL cholesterol. Until recently, the mechanism of its action has not been fully elucidated. However, it was speculated that niacin reduces the production of free fatty acids by inhibition of lipolysis in adipose tissue, which results in a reduced availability of substrate for VLDL synthesis in the liver..$^{95}$ Lately, this speculation was confirmed by the identification of a G-protein coupled receptor that is highly expressed in adipose tissue and to which niacin is a high affinity ligand. The binding of niacin to its receptor activates a G-protein signal, which reduces cAMP concentrations and thus inhibits lipolysis. However, a "rebound" increase in free fatty acids has been described. ${ }^{96}$ Karpe and Frayn suggest that the effect of niacin is on the down regulation of the activity of hormone sensitive lipase. ${ }^{96}$ The lowering of free fatty acid concentration results to a TG reduction, which in turn leads to increased HDL-cholesterol. ${ }^{96}$ Another potential mechanism by which niacin raises HDLcholesterol levels is through the stimulation of the ATP binding cassette Al-mediated transfer of cholesterol. ${ }^{97}$ It has also been suggested that niacin directly inhibits the synthesis of apo B containing lipoproteins in the liver. ${ }^{95}$

Fibrates are a class of hypolipidaemic drugs used to treat hypertriglyceridaemia and mixed hyperlipidaemia. Fibrates effectively lower plasma TG and increase HDL cholesterol levels. These drugs also reduce LDL cholesterol, particularly small dense LDL, which is associated with increased risk of 
Table 4 Drug interventions in studies treating dyslipidaemia in the metabolic syndrome

\begin{tabular}{|c|c|c|c|}
\hline Study (reference) & $\begin{array}{l}\text { Number of patients } \\
\text { with MetS* or T2DM† }\end{array}$ & Drug & Major CHD $\ddagger$ or CVD§ event (\%) \\
\hline AFCAPS/TexCaps ${ }^{87}$ & $155 \dagger$ & lovastatin & $44 \ddagger$ reduction \\
\hline LIPID $^{88}$ & $1077 \dagger$ & pravastatin & $19 \ddagger, 21 \% \S$ reduction \\
\hline CARE $^{89}$ & $586+$ & pravastatin & $25 \ddagger$ reduction \\
\hline \multirow{2}{*}{$4 \mathrm{~S}^{90}$} & $483 \dagger$ & simvastatin & $42 \ddagger$ reduction \\
\hline & $458^{*}$ & & $19 \ddagger$ reduction \\
\hline $\mathrm{HPS}^{91}$ & $5963+$ & simvastatin & $27 \ddagger$ reduction \\
\hline WOSCOPS $^{92}$ & $1691^{*}$ & pravastatin & $26 \S$ reduction \\
\hline VA-HIT ${ }^{93}$ & $627 \dagger$ & Gemfibrozil (fibrate) & $24 \S$ reduction \\
\hline $\mathrm{CDP}^{94}$ & $563^{*}$ & niacin & $24 \ddagger$ reduction \\
\hline
\end{tabular}

T2DM, type 2 diabetes mellitus; CHD, coronary heart disease; CVD, cardiovascular disease; AFCAPS/TexCAPS, air force/Texas coronary atherosclerosis prevention study; LIPID, long term intervention with pravastatin in ischaemic disease; CARE, cholesterol and recurrent events; 4S, Scandinavian simvastatin survival study; HPS, heart prevention study; WOSCOPS, West of Scotland coronary prevention study; DAIS, diabetes atherosclerosis intervention study; VA-HIT, Veterans Affairs high-density lipoprotein cholesterol intervention trial; CDP, coronary drug project. ${ }^{*}$ Corresponds to patients with MetS; tcorresponds to patients with T2DM; †corresponds to patients with CHD; §corresponds to patients with CVD.

atherosclerosis. The TG lowering activity of fibrates has been attributed to both inhibition of hepatic fatty acid synthesis and increased catabolism of TG rich lipoproteins. This increase in VLDL catabolism results from up-regulation of lipoprotein lipase expression and increased lipoprotein lipase activity because of a reduction in serum apo C-III levels. The increase in HDL cholesterol seen with fibrates correlates with increased expression of apo A-I and apo A-II. ${ }^{98}$ Several studies in animal models and cultured cells have established that the normolipidaemic effects of fibrates occur mainly through transcriptional modulation of target genes involved in fatty acid, TG, and cholesterol metabolism and also in lipoprotein formation and remodelling. ${ }^{99}$ This fibrate mediated transcriptional regulation is caused by binding and activation of a specific nuclear receptor termed peroxisome proliferators activated receptor $\alpha .^{99}$ Peroxisome proliferators activated receptor $\alpha$ is principally expressed in tissues exhibiting high rates of $\beta$ oxidation such as liver, kidney, heart, and muscle. ${ }^{100}$ Whereas, the role of fibrates in the regulation of plasma HDL cholesterol levels through changes in expression of plasma apo A-I, apo A-II, phospholipid transfer protein, lipoprotein lipase, and macrophage ATP binding cassette transporter Al transporter has been studied extensively, much less is known about fibrate dependent regulation of scavenger receptor class B type I. Recently,

\section{Key references}

- Wilson PW, Grundy SM. The metabolic syndrome: practical guide to origins and treatment: part I. Circulation 2003; 108:1422-4.

- Ginsberg HN, Huang LS. The insulin resistance syndrome: impact on lipoprotein metabolism and atherothrombosis. J Cardiovasc Risk 2000;7:325-18.

- Reilly MP, Rader DJ. The metabolic syndrome: more than the sum of its parts? Circulation 2003;108:154651.

- Ayyobi AF, Brunzell JD. Lipoprotein distribution in the metabolic syndrome, type 2 diabetes mellitus, and familial combined hyperlipidemia. Am J Cardiol 2003;92:27-33J.

- Kwiterovich PO Jr. Clinical relevance of the biochemical, metabolic, and genetic factors that influence lowdensity lipoprotein heterogeneity. Am J Cardiol 2002;90:30-47i.
Chinetti et al have shown that peroxisome proliferators activated receptor activation increased scavenger receptor class B type I protein levels in cultured human monocytes as well as in fully differentiated macrophages. ${ }^{101}$ In addition, fenofibrate treatment increased scavenger receptor class B type I protein content in macrophages of atherosclerotic lesions in apo E knockout mice. ${ }^{101}$ These findings suggest that fibrates might modulate HDL metabolism by increasing scavenger receptor class B type I expression in peripheral tissues.

Fibrates seem to be particularly effective in patients for whom a disturbance of the TG-HDL axis is the primary lipid disorder. Fibrates also seem to influence a number of emerging risk factors, including haemostatic and inflammatory markers and indicators of improved vascular wall biology, which may contribute to their cardioprotective effects.

Statins are commonly used to control blood lipid disorder. After its ingestion, the inactive lactone is hydrolysed in $\beta$ hydroxyl acid and inhibits the 3-hydroxy-3 methyl glutaryl coenzyme A reductase. The role of the regulatory enzyme 3hydroxy-3 methyl glutaryl coenzyme A reductase essentially limits the mevalonate pathway through which cells synthesise cholesterol. Although the pharmacokinetics and the metabolic pathway of statins are complex, they basically reduce the synthesis of LDL cholesterol by the liver and other cells and increase its catabolism. Currently, the effect of statins on the HDL metabolism is being studied. HDL and apo AI promote the removal and transfer of cholesterol from artery walls back to the liver. ${ }^{102}$ Statins have been shown to increase HDL cholesterol and apo AI. This increase may results from a decrease in the fractional catabolic rate of apo $\mathrm{AI}$ and/or increased production of apo AI through the action of its promoter, the peroxisome proliferators activated receptor. In addition, statins have non-lipid lowering pleiotropic effects such as an influence on thrombotic parameters, on inflammatory markers, and on the endothelium that are not discussed here.

Two additional potent drugs are peroxisome proliferators activated receptor $\gamma$ agonists and cholesteryl ester transfer protein inhibitors. Peroxisome proliferators activated receptor $\gamma$ is expressed at high levels in adipose tissue and it is activated by dietary fats, eicosanoids as well as by pharmacological drugs, such as glitazones. Glitazones exert a hypotriglyceridaemic action via peroxisome proliferators activated receptor $\gamma$ mediated induction of lipoprotein lipase expression in adipose tissue. ${ }^{100}$ Inhibition of cholesteryl ester transfer protein has been proposed as a strategy to raise HDL cholesterol levels. Cholesteryl ester transfer protein inhibitors 
such as JTT-705 and torcetrapid have been shown to increase plasma HDL levels in experimental animals, as well as in humans. ${ }^{103} 104$ In addition, torcetrapid has been shown to reduce slightly LDL levels both when given as monotherapy or in combination with a statin. ${ }^{103}$

\section{Combination treatment}

Combination therapy for dyslipidaemia may have advantages over single drug therapy improving lipoprotein risk factors when monotherapy fails. Such combination therapy includes statin/fibrate, statin/niacin, and statin/fish oils. Although the treatment with statin/fibrate, statin/niacin have been reported to increase the risk of drug induced myopathy and rhabdomyolysis, such combination therapies are considered safe. ${ }^{105}{ }^{106}$ Low or intermediate doses of statins (10-40 mg/ day) with fenofibrate (200 mg/day) or bezafibrate $(400 \mathrm{mg}$ / day) are considered effective and safe for the treatment of atherogenic dyslipidaemia. ${ }^{107}{ }^{108}$ It seems that the comparative safety of combined therapy may depend upon using low or moderate statin doses. In general, risk factors that predispose patients to myopathy caused by the above combinations include increased age, female sex, renal or liver disease, diabetes, hypothyroidism, debilitated status, surgery, trauma, excessive alcohol intake, heavy exercise, uncontrolled dose of niacin or fibrate and use of additional medications (cyclosporine, protease inhibitors, or drugs metabolised through cytochrome P450)..$^{109}{ }^{110}$ Patient education about warning signs of myopathy is of great importance.

Newer treatments, such as cholesterol absorption inhibitors, cholesteryl ester transfer protein antagonists, could also be used alone or in combination with other agents to optimise treatment.

Is treatment of MetS associated with reduced cardiovascular disease risk?

Because the MetS was defined relatively recently, part of the evidence that lipid changing drugs can reduce coronary vascular disease risk in the MetS comes from data of patients with type 2 diabetes mellitus, where the MetS is very common. ${ }^{15}$ Subgroup analyses of patients with diabetes in primary and secondary prevention trials show that treatment with lipid changing drugs can reduce the coronary vascular disease risk (table 4).

\section{CONCLUSIONS}

The constellation of characteristics called the MetS is an important risk factor for premature cardiovascular disease. Dyslipidaemia, the major constituent of the MetS, is characterised as an increased free fatty acid, TG, small, dense LDL and apo B levels, and low HDL cholesterol levels. The widely prevalent nature of the MetS emphasises the importance of its diagnosis and treatment. Weight reduction, increased physical activity, and moderate alcohol intake are first line treatments to improve lipid abnormalities in the MetS. Three major groups of lipid changing drugs such as niacin, fibrates, and statins have provided evidence supporting their use for treatment of MetS. Subgroup analyses of patients with diabetes (where MetS is very common) or MetS in primary and secondary prevention trials show that treatment with lipid changing drugs can reduce the coronary vascular disease risk. Further prospective investigations in large trials are required to confirm these findings. However, the treatment of dyslipidaemia is only one component. The management of the MetS is a "multi risk factor" approach where, except for cardiovascular disease, diabetes mellitus should be prevented as well.

\section{MULTIPLE CHOICE QUESTIONS (TRUE (T)/FALSE (F); ANSWERS AT END OF REFERENCES)}

1. Dyslipidaemia in the MetS is characterised by?
(A) Increased serum triglyceride levels

(B) Low serum HDL cholesterol level

(C) Small dense LDL cholesterol

(D) Raised cholesterol

(E) Raised free fatty acids

2. Adipose tissue produce adipocytokines such as:

(A) Leptin

(B) CETP

(C) Hepatic lipase

(D) Adiponectin

(E) $\mathrm{TNF} \alpha$

3. Small dense LDL have atherogenic properties such as:

(A) Increased LDL oxidation

(B) Increased arterial wall retention

(C) Increased LDL receptor clearance

(D) Prolonged resistance time in plasma

(E) Promotes endothelial dysfunction

4. Drugs changing lipids in MetS are:

(A) Statins

(B) Fibrates

(C) Nicotinic acid

(D) Cholestyramine

(E) $\omega-3$ fatty acids

5. The definition of MetS is based on existence of:

(A) Insulin resistance/hypertriglyceridaemia/low HDL

(B) Insulin resistance/hypertriglyceridaemia/hypertension

(C) Obesity/hypertriglyceridaemia/low HDL

(D) Blood glucose $\geqslant 6.1 \mathrm{mmol} / \mathrm{l} / \mathrm{low}$ HDL/obesity

(E) Insulin resistance/hypertriglyceridaemia/high HDL

\section{Authors' affiliations}

G D Kolovou, K K Anagnostopoulou, D V Cokkinos, 1st Cardiology Department, Onassis Cardiac Surgery Centre, Athens, Greece

Funding: none.

Conflicts of interest: none declared

\section{REFERENCES}

1 Reilly MP, Rader DJ. The metabolic syndrome: more than the sum of its parts? Circulation 2003;108:1546-51.

2 Ayyobi AF, Brunzell JD. Lipoprotein distribution in the metabolic syndrome, type 2 diabetes mellitus, and familial combined hyperlipidemia. Am J Cardiol 2003;92:27-33J.

3 Festa A, D'Agostino R Jr, Howard G, et al. Chronic subclinical inflammation as part of the insulin resistance syndrome: the insulin resistance atherosclerosis study (IRAS). Circulation 2000;102:42-7.

4 Messerli AW, Seshadri N, Pearce GL, et al. Relation of albumin/creatinine ratio to C-reactive protein and to metabolic syndrome. Am J Cardiol 2003;92:610-12.

5 Vaisanen S, Baumstark MW, Penttila I, et al. Small, dense LDL particle concentration correlates with plasminogen activator inhibitor type-1 (PAl-1) activity. Thromb Haemost 1997;78:1495-9.

6 Corella D, Ordovas JM. The metabolic syndrome: a crossroad for genotypephenotype associations in atherosclerosis. Curr Atheroscler Rep 2004;6:186-96.

7 Reaven GM. Banting lecture 1988. Role of insulin resistance in human disease. Diabetes 1988;37:1595-607.

8 Semenkovich CF. Fatty acid metabolism and vascular disease. Trends Cardiovasc Med 2004;14:72-6.

9 Alberti KG, Zimmet PZ. Definition, diagnosis and classification of diabetes mellitus and its complications. Part 1: diagnosis and classification of diabetes mellitus provisional report of a WHO consultation. Diabet Med 1998; 15:539-53. 
10 Executive Summary of the Third Report of The National Cholesterol Education Program (NCEP) Expert Panel on detection, evaluation, and treatment of high blood cholesterol in adults (Adult Treatment Panel III). Expert Panel on detection, evaluation, and treatment of high blood cholesterol in adults. JAMA 2001;285:2486-97.

11 Ford ES, Giles WH, Dietz WH. Prevalence of the metabolic syndrome among US adults: findings from the third national health and nutrition examination survey. JAMA 2002;287:356-9.

12 Lakka HM, Lakka TA, Tuomilehto J, et al. Abdominal obesity is associated with increased risk of acute coronary events in men. Eur Heart $J$ 2002;23:706-13.

13 Hsia J, Bittner V, Tripputi M, et al. Metabolic syndrome and coronary angiographic disease progression: the women's angiographic vitamin and estrogen trial. Am Heart J 2003;146:439-45.

14 Balkau B, Charles MA, Drivsholm T, et al. European Group for the study of insulin resistance (EGIR). Frequency of the WHO metabolic syndrome in European cohorts, and an alternative definition of an insulin resistance syndrome. Diabetes Metab 2002;28:364-76.

15 Isomaa B, Almgren P, Tuomi T, et al. Cardiovascular morbidity and mortality associated with the metabolic syndrome. Diabetes Care 2001 ;24:683-9.

16 Meigs JB, Wilson PW, Nathan DM, et al. Prevalence and characteristics of the metabolic syndrome in the San Antonio heart and Framingham offspring studies. Diabetes 2003;52:2160-7.

17 Ravussin E, Valencia ME, Esparza J, et al. Effects of a traditional lifestyle on obesity in Pima Indians. Diabetes Care 1994;17:1067-74.

18 Clement K, Boutin P, Froguel P. Genetics of obesity. Am J Pharmacogenomics 2002;2:177-87.

19 Matsuzawa Y, Funahashi T, Kihara S, et al. Adiponectin and metabolic syndrome. Arterioscler Thromb Vasc Biol 2004;24:29-33.

20 Malczewska-Malec M, Wybranska I, Leszczynska-Golabek I, et al. Analysis of candidate genes in Polish families with obesity. Clin Chem Lab Med 2004;42:487-93.

21 Merkel M, Eckel RH, Goldberg IJ. Lipoprotein lipase: genetics, lipid uptake, and regulation. J Lipid Res 2002;43:1997-2006.

22 van Dijk KW, Rensen PC, Voshol PJ, et al. The role and mode of action of apolipoproteins CIII and AV: synergistic actors in triglyceride metabolism? Curr Opin Lipidol 2004; 15:239-46.

23 Ashavaid TF, Shalia KK, Kondkar AA, et al. Gene polymorphism and coronary risk factors in Indian population. Clin Chem Lab Med 2002;40:975-85.

24 Lee KW, Ayyobi AF, Frohlich JJ, et al. APOA5 gene polymorphism modulates levels of triglyceride, HDL cholesterol and FER(HDL) but is not a risk factor for coronary artery disease. Atherosclerosis 2004;176:165-72.

25 Morabia A, Ross BM, Costanza MC, et al. Population-based study of SR-B genetic variation and lipid profile. Atherosclerosis 2004; 175:159-68.

26 Wang Y, Kurdi-Haidar B, Oram JF. LXR-mediated activation of macrophage stearoyl-CoA desaturase generates unsaturated fatty acids that destabilize ABCA1. J Lipid Res 2004;45:972-80.

27 Gudnason V, Kakko S, Nicaud V, et al. Cholesteryl ester transfer protein gene effect on CETP activity and plasma high-density lipoprotein in European populations. The EARS Group. Eur J Clin Invest 1999;29:1 16-28.

28 Sethi AA, Nordestgaard BG, Tybjaerg-Hansen A. Angiotensinogen gene polymorphism, plasma angiotensinogen, and risk of hypertension and ischemic heart disease: a meta-analysis. Arterioscler Thromb Vasc Biol 2003;23:1269-75.

29 Ji Q, lkegami H, Fujisawa T, et al. A common polymorphism of uncoupling protein 2 gene is associated with hypertension. J Hypertens 2004;22:97-102.

30 Wang JG, Liu L, Zagato L, et al. Blood pressure in relation to three candidate genes in a Chinese population. J Hypertens 2004;22:937-44.

31 Ginsberg HN, Huang LS. The insulin resistance syndrome: impact on lipoprotein metabolism and atherothrombosis. J Cardiovasc Risk 2000;7:325-31.

32 Genest JG Jr. Dyslipidemia and coronary artery disease. Can J Cardiol 2000; 16(suppl A):3-4A.

33 Ninomiya JK, L'Italien G, Criqui MH, et al. Association of the metabolic syndrome with history of myocardial infarction and stroke in the third national health and nutrition examination survey. Circulation 2004; 109:42-6.

34 Anderson JL, Horne BD, Jones $\mathrm{HU}$, et al, for the intermountain heart collaborative $(\mathrm{IHC})$ study. Which features of the metabolic syndrome predict the prevalence and clinical outcomes of angiographic coronary artery disease? Cardiology 2004;101:185-93.

35 Sacco RL, Benson RT, Kargman DE, et al. High-density lipoprotein cholesterol and ischemic stroke in the elderly: the Northern Manhattan stroke study. JAMA $2001 ; 285: 2729-35$

36 Trayhurn P, Beattie JH. Physiological role of adipose tissue: white adipose tissue as an endocrine and secretory organ. Proc Nutr Soc 2001;60:329-39.

37 Haluzik M, Parizkova J, Haluzik MM. Adiponectin and its role in the obesity induced insulin resistance and related complications. Physiol Res 2004;53:123-9.

38 Beltowski J. Adiponectin and resistin--new hormones of white adipose tissue Med Sci Monit 2003;9:RA55-61.

39 Drayna D, Jarnagin AS, McLean J, et al. Cloning and sequencing of the human cholesteryl ester transfer protein cDNA. Nature 1987;327:632-4.

40 Morton RE. Cholesteryl ester transfer protein and its plasma regulator: lipid transfer inhibitor protein. Curr Opin Lipidol 1999;10:321-7.

41 Arai T, Yamashita S, Hirano K, et al. Increased plasma cholesteryl ester transfer protein in obese subjects: a possible mechanism for the reduction of serum HDL cholesterol levels in obesity. Arterioscler Thromb 1994; 14:1129-36.

42 Gorter PM, Olijhoek JK, van der Graaf Y, et al, SMART Study Group. Prevalence of the metabolic syndrome in patients with coronary heart disease, cerebrovascular disease, peripheral arterial disease or abdominal aortic aneurysm. Atherosclerosis 2004;173:363-9.

43 Lewis GF, Uffelman KD, Szeto LW, et al. Interaction between free fatty acids and insulin in the acute control of very low density lipoprotein production in humans. J Clin Invest 1995;95:158-66.

44 Princen BHCMT, Romijn JA, Bisschop PH, et al. Endogenous cholesterol synthesis is associated with VLDL-2 apoB-100 production in healthy humans. $J$ Lipid Res 2003;44:1341-8.

45 Malmström R, Packard CJ, Watson TD, et al. Metabolic basis of hypotriglyceridemic effects of insulin in normal men. Arterioscler Thromb Vasc Biol 1997; 17:1454-64.

46 Lewis GF, Uffelman KD, Szeto LW, et al. Effects of acute hyperinsulinemia on VLDL triglyceride and VLDL apoB production in normal weight and obese individuals. Diabetes 1993;42:833-42.

47 Goldstein BJ. Insulin resistance: from benign to type 2 diabetes mellitus. Rev Cardiovasc Med 2003;4:S3-10.

48 McFarlane SI, Banerii M, Sowers JR. Insulin resistance and cardiovascular disease. J Clin Endocrinol Metab 2001;86:713-18.

49 Kwiterovich PO Jr. Clinical relevance of the biochemical, metabolic, and genetic factors that influence low-density lipoprotein heterogeneity. Am J Cardiol 2002;90:30-47i.

50 Packard CJ, Demant T, Stewart JP, et al. Apolipoprotein B metabolism and the distribution of VLDL and LDL subfractions. J Lipid Res 2000;41:305-18.

51 Ginsberg HN, Le N-A, Goldberg IJ, et al. Apolipoprotein B metabolism in subjects with deficiency of apolipoproteins C-III and Al: evidence that apolipoprotein C-III inhibits catabolism of triglyceride-rich lipoproteins by lipoprotein lipase in vivo. J Clin Invest 1986;78:1287-95.

52 Packard CJ. Triacylglycerol-rich lipoproteins and the generation of small, dense low-density lipoprotein. Biochem Soc Trans 2003:31:1066-9.

53 Lamarche B, Tchernof A, Mauriege P, et al. Fasting insulin and apolipoprotein $B$ levels and low-density lipoprotein particle size as risk factors for ischemic heart disease. JAMA 1998;279:1955-61.

54 Chait A, Brazg RL, Tribble DL, et al. Susceptibility of small, dense, low-density lipoproteins to oxidative modification in subjects with the atherogenic lipoprotein phenotype, pattern B. Am J Med 1993;94:350-6.

55 Kwiterovich PO Jr, Coresh J, Smith HH, et al. Comparison of the plasma levels of apolipoproteins $B$ and $A-1$, and other risk factors in men and women with premature coronary artery disease. Am J Cardiol 1992;69:1015-21.

56 Kwiterovich PO Jr, Coresh J, Bachorik PS. Prevalence of hyperapobetalipoproteinemia and other lipoprotein phenotypes in men (aged $<$ or $=50$ years) and women ( $<$ or $=60$ years) with coronary arterydisease. Am J Cardiol 1993;71:631-9.

57 Wilson PW, Grundy SM. The metabolic syndrome: practical guide to origins and treatment: part I. Circulation 2003;108:1422-4

58 Rust $\mathbf{S}$, Rosier $M$, Funke $H$, et al. Tangier disease is caused by mutations in the gene encoding ATP-binding cassette transporter 1. Nat Genet 1999:22:352-5

59 Kolovou G, Cokkinos DV. Low serum levels of high-density lipoprotein cholesterol and hypolipidaemic treatment. Curr Med Res Opin 2002; 18:265-8.

60 Kolovou G, Daskalova D, Petropoulos I, et al. Effect of baseline levels on response of high density lipoprotein cholesterol to hypolipidemic treatment. Am J Cardiol 2003;92:1339-42.

61 Robins SJ. Targeting low high-density lipoprotein cholesterol for therapy: lessons from the Veterans Affairs high-density lipoprotein intervention trial. Am J Cardiol 2001;88:19-23N

62 Taira K, Hikita M, Kobayashi J, et al. Delayed post-prandial lipid metabolism in subjects with intra-abdominal visceral fat accumulation. Eur J Clin Invest 1999;29:301-8.

63 Rebuffe-Scrive M, Lonnroth P, Marin P, et al. Regional adipose tissue metabolism in men and postmenopausal women. Int $J$ Obes 1987; 11:347-55.

64 Couillard C, Bergeron N, Prud'homme D, et al. Postprandial triglyceride response in visceral obesity in men. Diabetes 1998:47:953-60.

65 Mazzone T, Foster D, Chait A. In vivo stimulation of low-density lipoprotein degradation by insulin. Diabetes 1984;33:333-8.

66 Cummings MH, Watts GF, Umpleby AM, et al. Acute hyperinsulinemia decreases the hepatic secretion of very-low-density lipoprotein apolipoprotein B-100 in NIDDM. Diabetes 1995:44:1059-65.

67 AD. Hepatic uptake of chylomicron remnants. J Lipid Res 1997;38:2173-92.

68 Thompson GR, Naoumova RP, Watts GF. Role of cholesterol in regulating apolipoprotein B secretion by the liver. J Lipid Res 1996;37:439-47.

69 Patsch JR, Miesenbock G, Hopferwieser T, et al. Relation of triglyceride metabolism and coronary artery disease. Studies in the postprandial state. ArteriosclerThromb 1992;12:1336-45.

70 Kolovou GD, Daskalova D, Iraklianou SA, et al. Postprandial lipemia in hypertension. J Am Coll Nutr 2003;22:80-7.

71 Kolovou G. Anagnostopoulou K, Pilatis N, et al. Heterozygote men with familial hypercholesterolaemia (FH) may have an abnormal triglyceride response postprandially. Evidence for another predictor of vascular risk in FH. Int J Clin Practice 2005;59:31 1-17.

72 Steinberger J, Daniels SR, for American Heart Association Atherosclerosis, Hypertension, and Obesity in the Young Committee (Council on Cardiovascular Disease in the Young); American Heart Association Diabetes Committee (Council on Nutrition, Physical Activity, and Metabolism) Obesity, insulin resistance, diabetes, and cardiovascular risk in children: an 
American Heart Association scientific statement from the Atherosclerosis, Hypertension, and Obesity in the Young Committee (Council on Cardiovascular Disease in the Young) and the Diabetes Committee (Council on Nutrition, Physical Activity, and Metabolism). Circulation 2003; 107:1448-53.

73 Vinicor F. Is diabetes a public-health disorder? Diabetes Care 1994; 17(suppl 1):22-7.

74 Pinhas-Hamiel O, Dolan LM, Daniels SR, et al. Increased incidence of noninsulin-dependent diabetes mellitus among adolescents. J Pediatr 1996; 128:608-15.

75 Boden G. Fatty acids and insulin resistance. Diabetes Care 1996;19:394-5.

76 Haffner SM, Lehto S, Ronnemaa T, et al. Mortality from coronary heart disease in subjects with type 2 diabetes and in nondiabetic subjects with and without prior myocardial infarction. N Engl J Med 1998;339:229-34

77 Ayyobi AF, Brunzell JD. Lipoprotein distribution in the metabolic syndrome, type 2 diabetes mellitus, and familial combined hyperlipidemia. Am J Cardiol 2003;92:27-33J.

78 Goldstein J, Schrott H, Hazzard W. Hyperlipidemia in coronary heart disease, II: genetic analysis of lipid levels in 176 families and delineation of a new inherited disorder, combined hyperlipidemia. J Clin Invest 1973;52:1544-68

79 Rainwater DL, Mitchell BD, Mahaney MC, et al. Genetic relationship between measures of $\mathrm{HDL}$ phenotypes and insulin concentrations. Arterioscler Thromb Vasc Biol 1997;17:3414-19.

80 Sniderman AD, Castro Cabezas M, Ribalta J, et al. A proposal to redefine familial combined hyperlipidaemia -- third workshop on FCHL held in Barcelona from 3 to 5 May 2001, during the scientific sessions of the European Society for Clinical Investigation. Eur J Clin Invest 2002;32:71-3.

81 Jarvik GP, Brunzell JD, Austin MA, et al. Genetic predictors of FCHL in four large pedigrees. Influence of ApoB level major locus predicted genotype and LDL subclass phenotype. Arterioscler Thromb 1994;14:1687-94.

82 Chan DC, Barrett HP, Watts GF. Dyslipidemia in visceral obesity: mechanisms, implications, and therapy. Am J Cardiovasc Drugs 2004;4:227-46

83 Knopp RH, Walden CE, Retzlaff BM, et al. Long-term cholesterol-lowering effects of 4 fat-restricted diets in hypercholesterolemic and combined hyperlipidemic men: the dietary alternatives study. JAMA 1997; 278:1509-15.

84 Sudhop T, Lütjohann D, Kodal A, et al. Inhibition of intestinal cholesterol absorption by ezetimibe in humans. Circulation 2002;106:1943-8.

85 Simonen P, Gylling H, Howard AN, et al. Introducing a new component of the metabolic syndrome: low cholesterol absorption. Am J Clin Nutr 2000;72:82-8.

86 Chan DC, Watts GF, Barrett PHR, et al. Relationships between cholesterol homeostasis and triacylglycerol-rich lipoprotein remnant metabolism in the metabolic syndrome. Clin Sci 2003;104:383-8.

87 Downs JR, Clearfield M, Weis S, et al. Primary prevention of acute coronary events with lovastatin in men and women with average cholesterol levels: results of AFCAPS/TexCAPS. Air force/Texas coronary atherosclerosis prevention study. JAMA 1998;279:1615-22.

88 Keech A, Colquhoun D, Best J, et al, for LIPID Study Group. Secondary prevention of cardiovascular events with long-term pravastatin in patients with diabetes or impaired fasting glucose: results from the LIPID trial. Diabetes Care 2003;26:2713-21.

89 Goldberg RB, Mellies MJ, Sacks FM, et al. Cardiovascular events and their reduction with pravastatin in diabetic and glucose-intolerant myocardial infarction survivors with average cholesterol levels: subgroup analyses in the cholesterol and recurrent events (CARE) trial. The Care Investigators. Circulation 1998;98:2513-19.

90 Haffner SM, Alexander CM, Cook TJ, et al. Reduced coronary events in simvastatin-treated patients with coronary heart disease and diabetes or impaired fasting glucose levels: subgroup analyses in the Scandinavian simvastatin survival study. Arch Intern Med 1999;159:2661-7.
91 Collins R, Armitage J, Parish S, et al, Heart Protection Study Collaborative Group. MRC/BHF heart protection study of cholesterol-lowering with simvastatin in 5963 people with diabetes: a randomised placebo-controlled trial. Lancet 2003;361:2005-16.

92 Sattar N, Gaw A, Scherbakova O, et al. Metabolic syndrome with and without $\mathrm{C}$-reactive protein as a predictor of coronary heart disease and diabetes in the West of Scotland coronary prevention study. Circulation 2003; 108:414-19

93 Rubins HB, Robins SJ, Collins D, et al. Gemfibrozil for the secondary prevention of coronary heart disease in men with low levels of high-density ipoprotein cholesterol. Veterans Affairs High-Density Lipoprotein Cholesterol Intervention Trial Study Group. N Engl J Med 1999;341:410-18.

94 Canner PL, Furberg CD, Terrin ML, et al. Niacin decreases myocardial infarction and total mortality in patients with metabolic syndrome: results from the coronary drug project. J Am Coll Cardiol 2003:41(suppl A):291A.

95 Tatò F, Vega GL, Grundy SM. Effects of crystalline nicotinic acid-induced hepatic dysfunction on serum low-density lipoprotein cholesterol and lecithin cholesteryl acyl transferase. Am J Cardiol 1998;81:805-8.

96 Karpe F, Frayn KN. The nicotinic acid receptor--a new mechanism for an old drug. Lancet 2004;363:1892-4.

97 Rubic T, Trottmann M, Lorenz RL. Stimulation of CD36 and the key effector of reverse cholesterol transport ATP-binding cassette A1 in monocytoid cells by niacin. Biochem Pharmacol 2004;67:411-19.

98 Staels B, Auwerx J. Regulation of apo A-I gene expression by fibrates. Atherosclerosis 1998;137:S19-23.

99 Staels B, Dallongeville J, Auwerx J, et al. Mechanism of action of fibrates on lipid and lipoprotein metabolism. Circulation 1998;98:2088-93.

100 Gervois P, Torra IP, Fruchart JC, et al. Regulation of lipid and lipoprotein metabolism by PPAR activators. Clin Chem Lab Med 2000:38:3-11.

101 Chinetti G, Gbaguidi FG, Griglio S, et al. CLA-1/SR-BI is expressed in atherosclerotic lesion macrophages and regulated by activators of peroxisome proliferator-activated receptors. Circulation 2000;101:2411-17.

102 Martin G, Duez H, Blanquart C, et al. Statin-induced inhibition of the Rhosignaling pathway activates PPAR $\alpha$ and induces HDL apo A-I. J Clin Invest 2001;107:1423-32.

103 Brousseau ME, Schaefer EJ, Wolfe ML, et al. Effects of an inhibitor of cholesteryl ester transfer protein on $\mathrm{HDL}$ cholesterol. N Engl J Med 2004;350:1505-15

104 de Grooth GJ, Kuivenhoven JA, Stalenhoef AF, et al. Efficacy and safety of a novel cholesteryl ester transfer protein inhibitor, JTT-705, in humans: a randomized phase II dose-response study. Circulation 2002;105:2159-65.

105 Guyton JR. Combination drug therapy for combined hyperlipidemia. Curr Cardiol Rep 1999;1:244-50.

106 Streja D. Combination therapy for the treatment of dyslipidemia. Curr Opin Invest Drugs 2004;5:306-12.

107 Vega GL, Ma PT, Cater NB, et al. Effects of adding fenofibrate $(200 \mathrm{mg} /$ day) to simvastatin (10 mg/day) in patients with combined hyperlipidemia and metabolic syndrome. Am J Cardiol 2003;91:956-60.

108 Pauciullo P, Borgnino C, Paoletti R, et al. Efficacy and safety of a combination of fluvastatin and bezafibrate in patients with mixed hyperlipidaemia (FACT study). Atherosclerosis 2000;150:429-36.

109 Shek A, Ferrill MJ. Statin-fibrate combination therapy. Ann Pharmacother 2001;35:908-17

110 Wierzbicki AS, Mikhailidis DP, Wray R, et al. Statin-fibrate combination: therapy for hyperlipidemia: a review. Curr Med Res Opin 2003;19:155-68.

\section{ANSWERS}

1. (A) T, (B) T, (C) T, (D) F, (E) T; 2. (A) T, (B) T, (C) F, (D) T,

(E) T; 3. (A) T, (B) T, (C) F, (D) T, (E) T; 4. (A) T, (B) T, (C) T,

(D) $\mathrm{F}$, (E) $\mathrm{T}$; 5. (A) T, (B) T, (C) T, (D) T, (E) F. 